\title{
The emerging role of small RNAs in ovule development, a kind of magic
}

\author{
Rosanna Petrella $^{1} \cdot$ Mara Cucinotta $^{1} \cdot$ Marta A. Mendes ${ }^{1} \cdot$ Charles J. Underwood $^{2} \cdot$ Lucia Colombo $^{1}$
}

Received: 3 February 2021 / Accepted: 8 June 2021 / Published online: 17 June 2021

(c) The Author(s) 2021

\begin{abstract}
In plants, small RNAs have been recognized as key genetic and epigenetic regulators of development. Small RNAs are usually 20 to 30 nucleotides in length and they control, in a sequence specific manner, the transcriptional or post-transcriptional expression of genes. In this review, we present a comprehensive overview of the most recent findings about the function of small RNAs in ovule development, including megasporogenesis and megagametogenesis, both in sexual and apomictic plants. We discuss recent studies on the role of miRNAs, siRNAs and trans-acting RNAs (ta-siRNAs) in early female germline differentiation. The mechanistic complexity and unique regulatory features are reviewed, and possible directions for future research are provided.
\end{abstract}

Keywords Ovule $\cdot$ sRNA $\cdot$ Apomixis $\cdot \operatorname{RdDM} \cdot$ Female germline $\cdot$ Reproduction

\section{Ovule development and female germline establishment}

Ovules are the precursors of seeds and arise from the placenta, a meristematic tissue inside the ovary. Along the proximal-distal axis three regions differentiate: most distal is the nucellus, harboring the female germline; next is the chalaza, from which the integuments arise, and most proximal is the funiculus, which connects the ovule to the maternal tissue. The key steps occurring during ovule development in Arabidopsis are summarized in Fig. 1. In the primordium, one of the sub-epidermal cells of the nucellus, the archespore cell, differentiates into the megaspore mother cell (MMC), that undergoes meiosis to form four spores, in a process named megasporogenesis. The three most apical spores degenerate,

A contribution to the special issue 'Evolution of Plant Reproduction'.

Communicated by Frederic Berger.

Lucia Colombo

lucia.colombo@unimi.it

1 Dipartimento di Bioscienze, Università Degli Studi di Milano, Via Celoria 26, 20133 Milan, Italy

2 Department of Chromosome Biology, Max Planck Institute for Plant Breeding Research, Carl-von-Linné-Weg 10, 50829 Cologne, Germany while the remaining spore, the functional megaspore (FM), enters megagametogenesis. This process consists of three mitotic divisions followed by cellularization to form the embryo sac, the mature female gametophyte (Willemse 1992). The mature female gametophyte, surrounded by the inner and outer integuments, is a polarized structure, consisting of seven cells; we can distinguish two synergid cells, the egg cell, the central cell and three antipodal cells (Drews and Koltunow 2011; Fig. 1). The integuments develop from the chalaza and grow asymmetrically, producing an amphitropous shape (Robinson-Beers et al. 1992). They leave open a minute pore, the micropyle, through which the pollen tube will enter the embryo sac during double fertilization. Consequently, the two released sperm cell nuclei will fuse with the egg cell and the central cell, generating the zygote and the endosperm, respectively, whereas the integuments will develop into the seed coat (Hater et al. 2020).

There is a plethora of studies describing ovule development across evolution (reviewed by Gasser and Skinner 2018). In this review, we will consider the emerging role of small RNAs during ovule development, mainly focusing on the model species Arabidopsis. 
Megasporogenesis

Mencis (a)

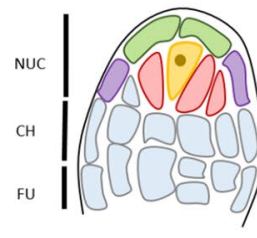

MMC differentiation (b)

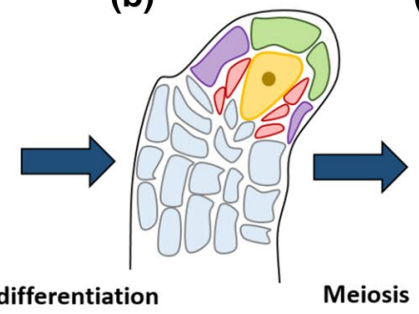

(c)

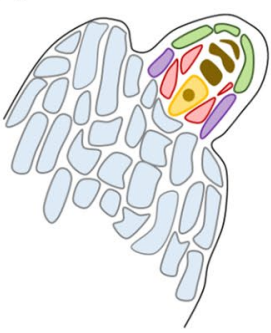

Megagametogenesis $\square$ Apical L1 cells
$\square$ Lower L1 cells $\quad \square$ Female reproductive cell

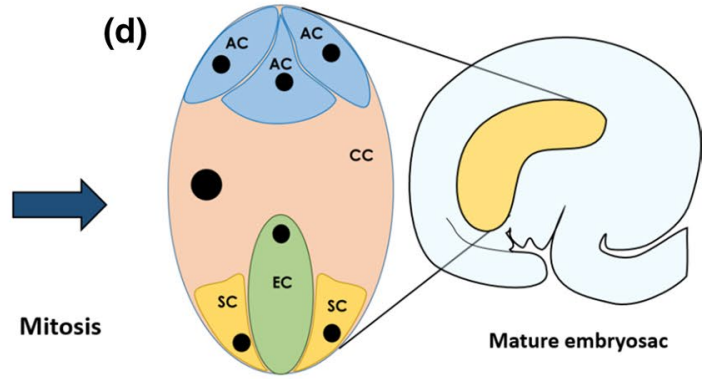

Fig. 1 Schematic representation of Arabidopsis thaliana ovule development. (a) to (c) Stages of megasporogenesis. a The ovule primordium presents a finger-like shape, wherein different domains can be distinguished: nucellus (nuc), chalaza (ch) and funiculus (fu). Within the nucellus, it is possible to further distinguish singular cell types: green and purple shading highlight the apical and basal epidermis, respectively, also known as L1 layer; dark pink marks the sub-epidermal nucellar cells or companion cells; in yellow, the female germline cell precursor, so called archesporial cell. b The female germline precursor differentiates into the megaspore mother cell (MMC); $\mathbf{c}$ The

\section{Small RNAs pathways: their biogenesis and processing}

A number of small RNA pathways have been reported in plants; while they may differ at the level of biogenesis and functional route of action, they share a single common goal-gene silencing. Gene silencing can occur by inhibiting transcription via DNA cytosine methylation (transcriptional gene silencing, TGS) or by targeting complementary mRNAs for degradation (post-transcriptional gene silencing, PTGS) and finally at the level of translation (translational gene silencing). In plants, small RNAs were first discovered as PTGS factors that act as a cellular defense mechanism against RNA viruses (Hamilton et al. 1999). Subsequently, they were shown to regulate the expression of transposable elements (TGS) and endogenous genes (reviewed by Borges and Martienssen 2015). In Fig. 2, we have schematically described the small RNA processing pathways mentioned in this review as they have been reported to have a role in ovule development.

In brief, miRNAs are 20-24 nucleotides in length and they are encoded by genes, producing a precursor transcript that forms a hairpin structure (pri-miRNA), which is then processed by a DICER-LIKE (DCL) protein, forming the pre-miRNA and successively the mature miRNA duplex; finally, only one strand is loaded into an ARGONAUTE (AGO) protein (reviewed by Borges and Martienssen 2015). In contrast to miRNAs, siRNAs can be produced by diverse routes; the best studied example is
MMC enters in meiosis, leading to the production of the four haploid megaspores; the most chalazal one survives and the other three undergo programmed cell-death (in brown). The surviving spore is named the functional megaspore. d Megagametogenesis starts when the functional megaspore undergoes three rounds of mitotic division. When the mature female gametophyte (or embryo sac) is completely formed, the micropylar pole comprises two synergid cells (sc), one egg cell (ec) and a diploid central cell (cc) whereas the chalazal pole presents three antipodal cells (ac). The inner and outer integuments develop from the chalaza and finally enclose the mature ovule

represented by siRNA biogenesis, which leads to RNAdirected DNA methylation (RdDM; Matzke and Mosher 2014). In canonical RdDM, a nascent RNA transcript of a transposable element (TE), usually transcribed by the RNA polymerase IV (Pol IV), is targeted by an RNA-dependent RNA polymerase (RDR) to produce a double-stranded RNA, which is then processed by a DCL protein into a siRNAs duplex; successively, only a single 24 nucleotide RNA strand is used by AGO proteins. In RdDM, the AGO proteins can also recruit DOMAINS REARRANGED METHYLTRANSFERASE 2 (DRM2), a DNA methyltransferase, to the transcribed locus to induce DNA cytosine methylation (Zhong et al. 2014). Furthermore, recent findings reported a yet uncharacterized role of AGO1 in the nucleus; here, guided by 21 nucleotide sRNAs, it can active gene transcription in concert with SWI/SNF chromatin remodelling complex (Liu et al. 2018).

Trans-acting siRNAs (ta-siRNAs) are encoded by a class of genes and they act in trans, as they are able to regulate target genes that are different from their original loci by PTGS and, in some instances, induce DNA methylation of the TAS loci themselves. Ta-siRNA biogenesis involves the targeting of a long TAS RNA precursor by miRNA-guided AGO cleavage, followed by the respective synthesis (by RDR6) and stabilization (by SUPPRESSOR OF GENE SILENCING 3; SGS3) of dsRNAs. These dsRNAs are processed by DCL and AGO proteins to form a 21 nucleotide ta-siRNA that can act either through PTGS to silence developmental regulators or TGS, targeting the corresponding TAS loci (Matzke and Mosher 2014). 

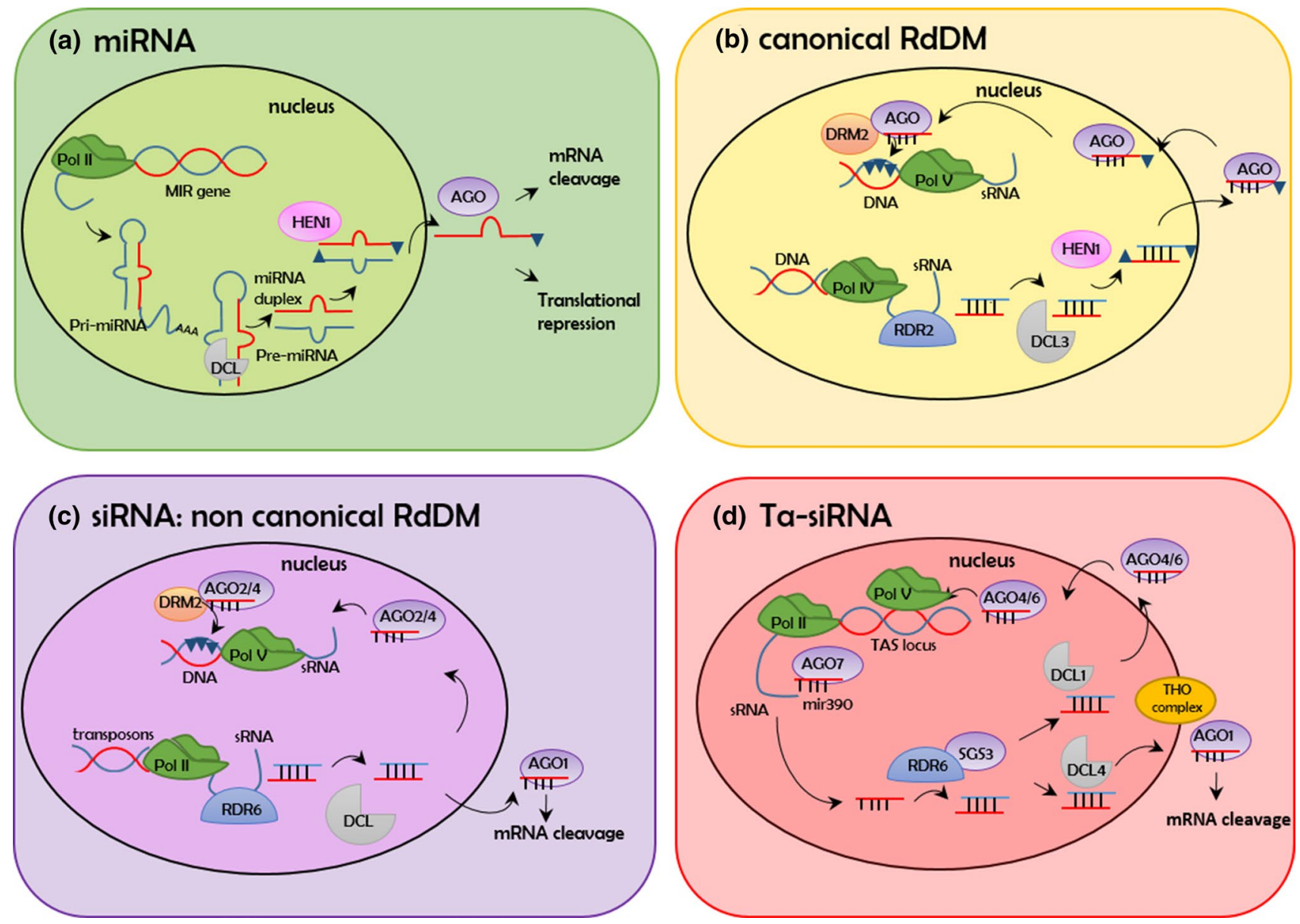

\section{(d) Ta-siRNA}

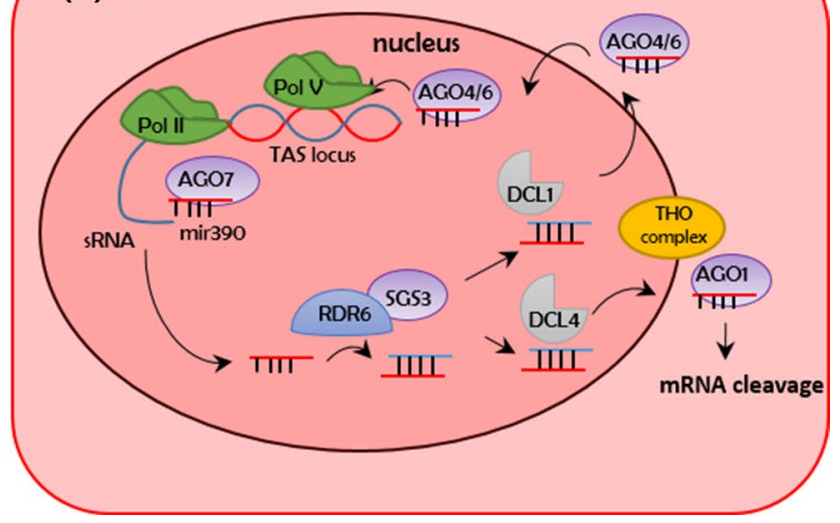

Fig. 2 Summary of small RNAs biogenesis and processing. a RNA polymerase II (Pol II) is required for the transcription of long primary single stranded miRNA (pri-miRNA); a hairpin structure is then formed by sequence complementarity and the pri-miRNA is cleaved by DICER-LIKE (DCL) proteins, forming the miRNA precursor (pre-miRNA); it is processed by DCL to form miRNA duplexes (Xie et al. 2005). miRNA duplexes are 2'-O-methylated at both 3 'ends by HUA ENHANCER 1 (HEN1), a mechanism that protects them from degradation and uridylation; mature miRNA duplexes are recognized and cleaved by the ARGONAUTE (AGO) proteins (Vaucheret 2008); they are successively exported to the cytosol as AGO1:miRNA complexes (Bologna et al. 2018). b The canonical RNA-dependent DNA Methylation (RdDM) pathway requires Pol IV to transcribe transposable elements, RNA-DEPENDENT RNA POLYMERASE 2 (RDR2) to produce dsRNAs, DCL3 to process dsRNAs to 24-nucleotide siRNAs, which are stabilized by methylation at their 3'-OH groups by HEN1 and loaded onto AGO4, AGO6, and/or AGO9. During Pol $\mathrm{V}$ mediated transcription, the AGO4 recruits DOMAINS REARRANGED METHYLTRANSFERASE 2 (DRM2), that is responsible for de novo methylation at the homologous genomic sites, provoking transcriptional gene silencing (TGS). c A slightly different path-

\section{Role of RdDM and ta-siRNAs in female germline specification and progression}

During ovule development, only one cell of the nucellus differentiates into the MMC. The genetic network controlling way includes the RDR6-dependent RdDM. Young transposons are initially transcribed by Pol II to produce RNAs from transposable elements. Some of these Pol II transcripts can be copied by RDR6 to produce dsRNAs, which are processed by DCL2 and DCL4 into 21-22-nucleotide siRNAs, resulting in AGO1-mediated PTGS of transposon derived RNAs. These dsRNAs can also initiate low levels of de novo DNA methylation, which initiates the canonical RdDM pathway in a manner that is dependent on AGO2, Pol V and DRM2. d Trans-acting siRNAs (ta-siRNAs). ta-siRNA biogenesis involves the targeting of a Pol II generated long non-coding TAS RNA precursor by miRNA-guided AGO cleavage (miR390-AGO7), followed by the respective synthesis (by RDR6) and stabilization (by SUPPRESSOR OF GENE SILENCING 3; SGS3) of dsRNAs. These dsRNAs are processed by DCL4 and loaded into AGO1 proteins for PTGS, while for non-canonical RdDM they are processed by DCL1, loaded into AGO4/6, can induce DNA methylation at the corresponding TAS loci (Matze and Mosher 2014). Ta-siRNAs biogenesis can be further controlled by the THO complex, in particular by TEX1. The THO complex is important to export the ta-siRNAs from the nucleus to the cytosol

MMC specification has been recently reviewed by Pinto et al. (2019). The pre-meiotic ovules of Arabidopsis argonaute 9 (ago9) mutants have supernumerary MMC-like cells; thus, it has been suggested that AGO9 is required to inhibit the somatic cells surrounding the MMC to acquire a 
germ cell fate (Olmedo-Monfil et al. 2010; Rodríguez-Leal et al. 2015). AGO9 is reported to primarily act in a noncell-autonomous manner, as it is preferentially expressed in the somatic cells of the L1 layer of the pre-meiotic ovule. It is worth mentioning that the protein was reported to be transiently and sporadically expressed in the nucleus of the MMC, suggesting a yet uncharacterized role for AGO9 in promoting female germline establishment and progression (Rodríguez-Leal et al. 2015). The ortholog of AGO9 in Zea mays, AGO104, is important for male and female gametophyte development; in fact, the mutant agol04 is impaired in chromatin condensation during meiosis and subsequently chromosomes fail to segregate properly (Singh et al. 2011). Similar to $A G O 9$, also $A G O 104$ expression is preferentially restricted to the somatic nucellar cell of the ovule primordium. Despite their similar expression domain in the ovule, AGO104 and AGO9 seem to act in two different ways since AGO104 most likely represses somatic fate in germ cells, whereas $A G O 9$ inhibits germ cell identity in somatic tissue (Olmedo-Monfil et al. 2010; Singh et al. 2011; RodríguezLeal et al. 2015; Mendes et al. 2020). AGO9 is preferentially associated with 24 nucleotide siRNAs derived from TEs (Olmedo-Monfil et al. 2010; Havecker et al. 2010). Furthermore, it has been shown that agol04 mutants have reduced non-CG DNA methylation and increased transcription of centromeric repeats. These observations suggest that AGO9/ AGO104 in plants perform similar functions as the animal PIWIs that promote oogenesis by maintenance of transposon silencing in the germline genome (Houwing et al. 2008; Singh et al. 2011).

Similar to the ago 9 mutant, plants lacking the canonical RdDM factors RDR2, DCL3 and Pol IV/Pol V also exhibit a multiple MMC-like cells phenotype (Olmedo-Monfil et al. 2010). Intriguingly, the non-canonical RdDM $r d r 6$ showed extra numerary MMC-like cells in the nucellus of pre-meiotic ovules (Olmedo-Monfil et al. 2010; Mendes et al. 2020). A similar phenotype has been recently reported for the double mutant in DRMI and DRM2 (Mendes et al. 2020), whose proteins catalyze the DNA methylation of TEs (Law and Jacobsen 2010). All these data suggest that the RdDM pathway is required to confine germ cell identity to a single cell in the ovule. The homologs of DRM1 and DRM2 in maize (i.e., DMT102 and DMT103) are both expressed in a restricted portion of the nucellus during megasporogenesis and their loss-of-function leads to the induction of an apomixis-like phenotype (further described in this review), supporting a conserved role for the DNA methylation pathway during female germline formation (Garcia-Aguilar et al. 2010).

Despite the presence of supernumerary MMC-like cells in the nucellus of mutants impaired in RdDM, only one MMC will undergo meiosis (Olmedo-Monfil et al. 2010; Mendes et al. 2020), suggesting that other factors are required to promote germ cell fate in somatic cells. Mendes et al. (2020) investigated the regulatory pathways that act upstream and downstream of RdDM activity and reported that SEEDSTICK (STK), a MADS domain transcription factor that controls ovule identity (Pinyopich et al. 2003; Favaro et al. 2003), directly binds the regulatory region of $A G O 9$ and $R D R 6$ to promote their expression solely in the lower cells of the L1 layer. Indeed, the stk mutant shows supernumerary MMC-like cells and a reduction in $A G O 9$ and RDR6 expression (Mendes et al. 2020). In the nucellus, the RdDM pathway is required to limit SPOROCYTELESS/NOZZLE (SPL/ $N Z Z$ expression; as a consequence, SPL/NZZ is confined to the $\mathrm{L} 1$ cells at the top of the nucellus (Mendes et al. 2020). SPL/NZZ is required for germline differentiation, evidenced by the fact that $s p l / n z z$ mutants fail to form the MMC (Yang et al. 1999; Schiefthaler et al. 1999). Knock-out mutations in RdDM machinery genes (i.e., AGO9, DRM1 and DRM2) cause an ectopic expression of $S P L / N Z Z$, which is most likely responsible for the formation of the extra numerary MMC-like cells, observed in the mutants described above.

These findings suggest that although the somatic cells surrounding the MMC have somehow the competence to acquire MMC identity, other factors are required to differentiate a fully functional MMC, committed to meiosis (Mendes et al. 2020). Intriguingly, Nonomura et al. (2007) proposed that in Oryza sativa there is an excess of archesporial cells in the pre-meiotic ovule but only one undergoes a differentiation process to ultimately form the MMC, most likely lead by the SPL/NZZ ortholog (Ren et al. 2018).

In animals, small RNA silencing pathways have been shown to functionally interact with the Vasa family of RNA helicases in the germline (Gustafson et al. 2010). Despite the fact that no Vasa proteins have been found in the plant kingdom, other RNA helicases might have adopted a similar function. For example, the RNA Helicases MNEM (MEM) has been reported to play an important role during MMC differentiation. The heterozygous $M E M / m e m$ mutant is indeed characterized by supernumerary MMC-like cells, phenocopying the reported small RNA silencing machinery mutants (Olmedo-Monfil et al. 2010; Schmidt et al. 2011; Mendes et al. 2020). Thus, it had been proposed that MEM might act in combination with the small RNA pathway to restrict the female germline identity to a single cell in the ovule (Schmidt et al. 2011). Notably, the authors reported that $M E M$ expression resulted enriched in the MMC, indicating that MMC suppresses the development of additional germline precursors in a non-autonomous fashion. All in all, these findings suggest the requirement of multiple genetic factors involved in restricting germ cell fate to a single cell, the MMC (Fig. 3).

Ta-siRNAs play a fundamental role throughout plant development (Deng et al. 2018); mutants in ta-siRNA biogenesis factors like $\operatorname{sgs} 3$ and $r d r 6$ showed extra numerary 


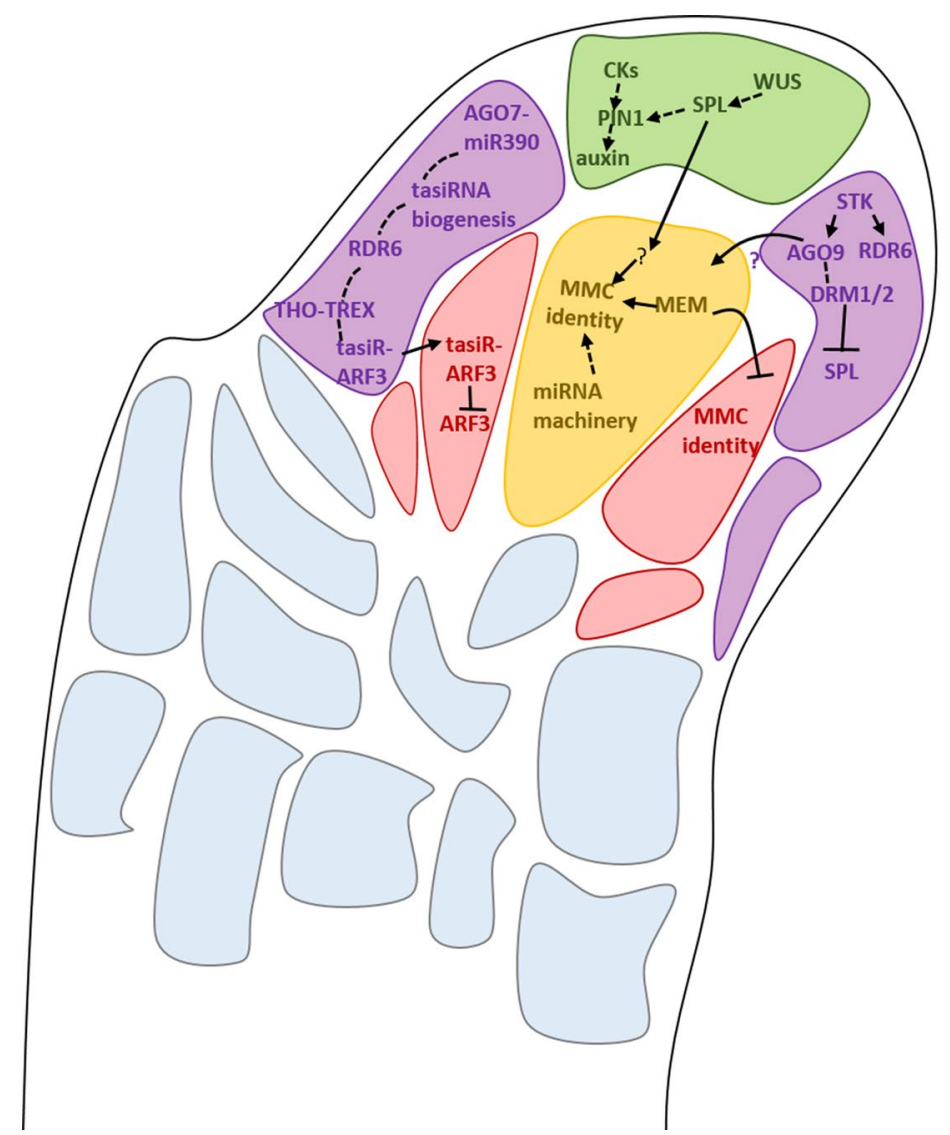

\author{
Apical L1 cells \\ Lower $\mathbf{L} 1$ cells \\ MMC \\ Companion cells
}

Fig. 3 Summary of the key small RNA pathways involved in female germline differentiation. In the Arabidopsis ovule the megaspore mother cell (MMC), in yellow, is surrounded by the companion cells (in red) and the L1 layer (in green and purple). The MMC correct differentiation and identity depends on the proper establishment of cell specific small RNA-dependent pathways. The MNEME (MEM), an RNA helicase known to interact with small RNA pathways, is expressed within the MMC; the respective mutant presents multiple MMC-like cells (Gustafson et al. 2010), meaning that its presence is important to restrict MMC cell fate to a single cell. Similarly, several mutants of the RdDM pathway were described as presenting the same ago 9 phenotype (e.g., the rna-dependent rna polymerase 2 and $6(r d r 2$ and $r d r 6)$ and the dicer-like 3 (dcl3) (Olmedo- Monfil et al. 2010). The MADS domain transcription factor SEEDSTICK (STK) was shown to directly activate $A G O 9$ and RDR6, and their specific control in the basal L1 cells was shown to be important for a small
RNA-dependent methylation pathway, as mutants for DOMAINS REARRANGED METHYLTRANSFERASES 1 and 2 (DRM1 and $D R M 2)$ resulted in multiple MMC-like phenotype as well. This STK-RdDM pathway results in the small RNA silencing (directly or indirectly) of the putative transcription factor SPOROCYTELESS/ NZZ (SPL/NZZ), whose expression should be only confined to the apical L1 cells (Mendes et al. 2020). SPL/NZZ and WUSCHEL (WUS) act together in the apical L1 cells to drive the expression of PIN-FORMED1 (PIN1); its proper localization is further controlled by cytokinins, which are important for the correct auxin flux. SPL/ NZZ (and WUS) might send a signal (?) to the hypodermal cell (in yellow), that then acquires MMC identity. Trans-acting short interfering RNA (ta-siRNA) TAS3 pathway mediated by RDR6 and TEX1 is involved in the repression of AUXIN RESPONSIVE FACTOR 3 (ARF3), a positive regulator of MMC identity

percentage of mature ovules show twin embryo sacs, suggesting that the extra MMC might generate an unreduced female gametophyte. Analysis of the $j 66$ mutant demonstrated that the mutation was located in the TEX1 gene, which encodes for one of the components of the THO/ TREX complex. THO/TREX complex plays an important role in small interfering RNA-dependent processes in plants; in fact, its impairment leads to defects in small RNA biogenesis, export and processing (Francisco-Mangilet et al. 2015). To confirm the role of the THO/TREX complex in germline specification, several THO core complex encoding form the functional megaspore (FM). Interestingly, a low 
gene mutants were examined (Masuda et al. 2005; Yelina et al. 2010; Su et al. 2017). Both hprl-6 and tho6 mutants presented extra numerary MMC-like cells in pre-meiotic ovules, suggesting an important function for the THO core complex in MMC differentiation. The THO/TREX complex is involved in ta-siRNA biogenesis by transporting ta-siRNA precursors from the nucleus to the cytoplasm (Jauvion et al. 2010; Yelina et al. 2010). Long non-coding RNAs from the TAS3 loci are targeted by the miR390-AGO7 complex to trigger tasiR-ARF production. The cleaved transcripts are then stabilized by SGS3 and converted into dsRNA by RDR6 (Kumakura et al. 2009). The ta-siRNA-ARF complex is finally recruited into an AGO1-containing effector complex to repress AUXIN RESPONSE FACTOR 3 (ARF3) expression (Fahlgren et al. 2006; Montgomery et al. 2008). The TAS3 gene is expressed broadly in the ovule, whereas $S G S 3$ and $A G O 7$ expression is confined to the epidermis layer, most likely to limit tasiR-ARF biogenesis to the L1 cells in the nucellus. Su et al. $(2017 ; 2020)$ showed a nonautonomous activity for $A R F 3$ in female germline specification. In fact, $A R F 3$ is a positive regulator for MMC identity; the specific expression of $A R F 3 m$ (resistant to regulation by tasiR-ARFs) in the hypodermal cells (i.e., companion cells) is sufficient to trigger the formation of extra MMC-like cells in pre-meiotic ovules, whereas its ectopic expression in the outermost epidermal cell of the L1 layer does not increase the number of MMC per ovule (Su et al. 2020). Thus, the data reported confirm that hypodermal cells have the "potential" to acquire MMC fate. Despite this observation, the extra numerary MMC-like cells do not enter meiosis; hence, further factors are required for the progression of the female germline in those cells. L1 and L2 domains are two specialized cell layers in the nucellus, characterized by distinct transcriptomes (reviewed by Pinto et al. 2019). Therefore, it might be that uncharacterized factors, absent in the L1 layer, are fundamental for complete MMC differentiation and competence to enter meiosis. Su and collaborators (2020) proposed that tasiR-ARF3 can move in two directions: from the epidermal to the hypodermal cell, and from the chalaza to the nucellus, to restrict $A R F 3$ expression to the chalaza.

To determine the regulatory network downstream of $A R F 3$ in MMC specification, Su et al. (2020) performed a transcriptome analysis to identify differentially expressed genes (DEGs) in the $p W R K Y 28$ :ARF3m-mCitrine line that specifically drives the expression of ARF3m in the hypodermal cells surrounding the MMC. They pointed out that several factors involved in auxin and cytokinins (CKs) signal transduction pathways were deregulated. The results from Su and collaborators $(2017,2020)$ unravel a novel role for ARFs in the early step of ovule development, proposing that phytohormones might play an important role in MMC specification and development. The contribution of CKs and auxin in MMC formation has been previously suggested. In fact, $S P L / N Z Z$ is reported to act downstream of CKs, and to promote the expression of the auxin efflux carrier protein PIN-FORMED 1 (PIN1) in the nucellus, required for MMC identity (Bencivenga et al. 2011, 2012). Furthermore, the homeodomain transcription factor WUSCHEL (WUS; Groß-Hardt and Laux 2003) was suggested to have a role in assuring MMC differentiation by activating SPL/NZZ expression in the nucellus; as matter of fact, the wus mutant sporadically exhibited ovules without MMC, also shown for pin1 and spl/nzz mutants (Yang et al. 1999; Schiefthaler et al. 1999; Groß-Hardt and Laux 2003; Bencivenga et al. 2011; Bencivenga et al. 2012). Recent findings by Zhao and collaborators (2017) addressed a new role for WUS regulation in the megasporogenesis process; indeed, the direct inactivation of the homeodomain factor by Retinoblastoma homolog RBR1 is necessary for the determination of meiotic cell division program in the MMC.

The involvement of diverse factors and genetic networks in MMC differentiation and megasporogenesis intriguingly suggests that different pathways might act in concert to assure the proper establishment and progression of the female germline, through the regulation of hub factors.

\section{The miRNA machinery plays an important role in megasporogenesis}

The microRNA machinery has also been shown to have a role in female germline establishment. It has been reported that mutation in miRNA pathway components affects female germline specification (Oliver et al. 2017). Mutants in genes encoding for components of the different steps of the miRNA pathway have been analyzed: $D C L 1$ and $H Y P O$ NASTIC LEAVES 1 (HYL1), required for miRNA precursor processing; HUA ENHANCER 1 (HEN1), involved in miRNA duplex stabilization; HASTY (HST), required in nuclear export of miRNAs and finally $A G O 1$, involved in silencing of miRNA targets (reviewed by Wang et al. 2019). Although the mutants do not show a fully penetrant female sterility phenotype, they partially failed to form the MMC (Oliver et al. 2017). Loss of function of miRNA machinery also resulted in the deregulated expression of several genes involved in meiosis and chromatin condensation, many of which could not be explained by direct targeting by miRNAs (Oliver et al. 2017; Wang et al. 2019). Among them, SWITCH 1 (SWI1), a chromatin remodelling gene involved in meiotic recombination and sister chromatid cohesion, $M M S$ AND UV SENSITIVE 81 (MUS81), involved in promoting crossing over (CO) formation, $S M C 4 A$, which encodes for a protein of the condensin complex, and TOPOISOMERASE II (TOPII), which is involved in CO resolution, are predicted targets of miRNAs, according to psRNATarget (Olivier et al. 
2015; Dai et al. 2018); they were all overexpressed in the miRNA machinery mutants (Oliver et al. 2017). In particular, MUS81 was found to be a putative target of miRNA854ae; miRNA854 has been found in wild-type flowers, but is absent in $d c l l$, hyll and hen 1 mutants (Arteaga-Vázquez et al. 2006). Therefore, Oliver and colleagues (2017) proposed that the impairment of miRNA machinery leads to a deregulation of key components of meiotic recombination and chromatin condensation in archesporial cells, thus affecting pre-meiotic cell divisions. As a matter of fact, these mutations showed defects in chromatin condensation during first meiotic division and meiosis abortion; in particular, the mutants analyzed (see above) shared several meiotic phenotypes (e.g., decreased number of cells that enter meiosis, increased number of chiasmata, and partial chromosome decondensation from pachytene to metaphase I). Intriguingly, Oliver and colleagues (2014) reported a novel role of several AGO proteins during microsporogenesis in the male meiocytes. Despite the observation that impairment in AGO proteins activity does not significantly affect the meiotic process, the authors showed that ago9-1 mutants were characterized by an higher frequency of chromosome interlocks in mid-late pachytene, while the ago2-1 mutant had a modest increase in chiasma frequency. Those observations suggest that different classes of AGO protein may be involved in the meiotic process. Given the reported expression of AGO2, AGO5 and AGO9 in the ovules (Olmedo-Monfil et al. 2010; Wuest et al. 2010), it is tempting to speculate that the said proteins might also have a role in meiotic progression in the MMC. All in all, these studies have contributed to shedding light into the role of miRNA machinery during the early phases of germline development (Fig. 3).

\section{Role of small RNA pathways during megagametogenesis}

At the end of megasporogenesis, three of the four megaspores degenerate, whereas the one located at the chalazal pole, the functional megaspore (FM), will survive and divide mitotically to generate the mature embryo sac. Tucker et al. (2012) reported a small RNA mutant that affects female gametogenesis. They reported that a mutant in the AGO5 gene was defective in the gametogenesis process. In particular, the mutation generates a semi-dominant AGO5 protein, named AGO5-4, active in somatic cells flanking the functional megaspore and responsible for inhibiting female gametophyte progression. Notably, full knock-out mutation of ago5 had no effects on female gametophyte development, suggesting that in ago5-4 are compromised pathway(s) that are not normally targeted by AGO5. The predicted AGO5-4 protein shared a similar protein structure with some viral suppressor proteins, such as P1/Hc-Pro and P19, that inhibit miRNA and siRNA functions (Kasschau et al. 2003). Interestingly, the specific expression of $\mathrm{P} 1 / \mathrm{Hc}$-Pro in the AGO5 expression domain triggered female gametophyte abortion, proposing the existence of a somatic sRNA pathway that promotes megagametogenesis (Tucker et al. 2012). These results suggested that the progression of megagametogenesis might be somehow dependent on a fine balance of small RNAs in the somatic cells of the ovule (Fig. 4).

The closest rice homolog of AGO5, MEIOSIS ARRESTED AT LEPTOTENE 1 (MEL1) is reported to be important in promoting germline development and maintaining female and male germ cell identity; indeed, the mutant is characterized by the disruption of spores formation during meiosis. MEL1 is specifically expressed in germ cells, suggesting that a cell-autonomous pathway acts to specify germline fate. MEL1 preferentially binds $5^{\prime}$ cytosine of 21 nucleotide phased small interfering RNAs (phasiRNAs) (Komiya et al. 2014). Interestingly, Nonomura and collaborators (2007) reported that the mutation in MEL1 locus is associated with a significantly reduced $\mathrm{H} 3 \mathrm{~K} 9$ dimethylation. Since RNAi and AGO proteins are known to play a role in TGS in other systems (Volpe et al. 2002), the authors speculated a relationship between MEL1 function and H3K9 dimethylation. PhasiRNA biogenesis during rice reproductive development is triggered by miR2118; mutation of miR2118 leads to complete male and female sterility, suggesting an important role for phasiRNAs in rice reproduction (Araki et al. 2020).

Recent studies have further improved our knowledge of the role of small RNA pathways during megagametogenesis. Sprunck et al. (2019) investigated small RNA pathways contributing to egg cell differentiation, by the use of proliferating callus tissue. With this approach, it was possible to successfully identify miRNAs differentially expressed in the egg cell and in other cell types within the female gametophyte, such as synergid cells.

In addition, distribution of small RNAs in egg cells and sperm cells was analyzed in rice ( $\mathrm{Li}$ et al. 2020a). It has been shown that both egg cells and sperm cells had reduced abundance of miRNAs relative to siRNA and that each gamete expressed a diverse set of miRNAs. Furthermore, Li and collaborators (2020a) reported that in both gametes, patterns of CHH methylation, typically associated with RdDM, were similar to vegetative tissues, although lower in magnitude.

Jullien et al. (2020) elucidated the expression patterns of all Arabidopsis $A G O$ genes in the mature ovule. They reported accumulation of almost all AGO proteins in the mature egg cell, compared to the other cell types of the embryo sac. All in all, these studies are novel and comprehensive resources for the further study of small RNAs involvement in egg cell differentiation and fertilization in Arabidopsis (Sprunck et al. 2019; Jullien et al. 2020). 


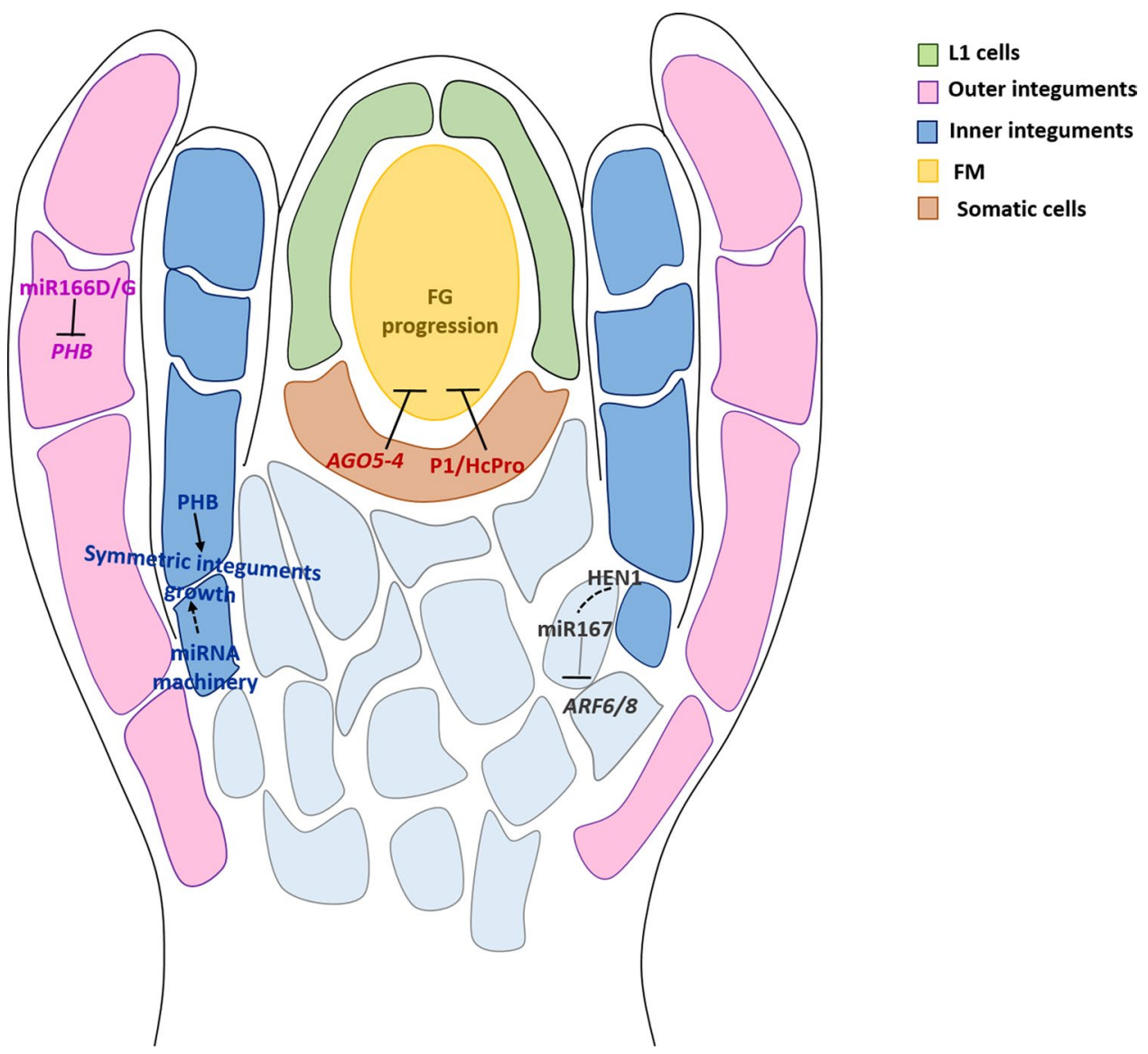

Fig. 4 Summary of the key small RNAs pathways implicated in megagametogenesis activation and integuments formation. Upon megasporogenesis, the functional megaspore is formed and megagametogenesis takes place; at the same time inner and outer integuments start to develop and to elongate. Several miRNA pathways have been demonstrated to have an important role in integument growth. miR167 targets AUXIN RESPONSE FACTOR 6 (ARF6) and ARF8, and this regulation is important for the asymmetric integument growth leading to abnormal embryo sac development.

\section{miRNAs are of pivotal importance for integuments development}

Several players of miRNA machinery as well as different miRNAs have been shown to have important roles in integument growth. The integuments initiate from the chalaza region during the early stage of ovule development and grow in order to enclose and protect the entire gametophyte. It has been reported that a cross-talk between integuments and developing female gametophyte is constantly required for a proper ovule development and female germline progression (reviewed by Bencivenga et al. 2011).

Mutants in DCL1 presented ovules with severe integuments defects (Robinson-Beers et al. 1992; Lang et al. 1994; Ray et al. 1996; Fukudome et al. 2017); this result indicated that miRNAs could operate during ovule development to
A similar situation was encountered in hen 1 mutations; miR165 and miR166 silence the HD-ZIP III family targets, including $P H A B U$ LOSA (PHB), PHAVOLUTA (PHV) and CORONA (CNA; Sakaguchi et al. 2012). In fact, the corresponding mutants present defects in inner and outer integuments development. Gametogenesis is impaired in an ARGONAUTE 5 (AGO5) mutant, showing a high percentage of ovule abortion; the predicted AGO5 protein shares a similar protein structure with some viral suppressor proteins, e.g., P1/Hc-Pro and $\mathrm{P} 19$, that are known to inhibit miRNA and siRNA functions

regulate a range of genes necessary for proper integuments development (Schauer et al. 2002).

Indeed, after several years, miR167 and miR165/166 have been shown to be required for integument growth. The miR167 targets ARF6 and ARF8 in both ovule and anthers (Wu et al. 2006). miR167-resistant ARF6 (mARF6) plants were sterile due to defects in ovules, presenting developmentally arrested integuments (Wu et al. 2006). miR167 is present exclusively in seed plants, suggesting that it could have arisen together with the formation of sporophytic structures that protect the female gametophyte (Wu et al. 2006). It has been reported that miR167a also regulates $A R F 6$ and $A R F 8$ expression during early stages of seed development, as the miR167a mutant failed to produce normal embryos and endosperm; this phenotype could be suppressed by mutation in either ARF6 or ARF8 (Yao et al. 2019). 
Recently, two other miRNA-processing proteins HUA1 and HYL1 have been reported to be required for normal integument growth (Wei et al. 2020). HYL1, a dsRNAbinding protein, interacts with DCL1 during the processing of pri-miRNAs (Kurihara et al. 2006), while HEN1 is a O-methyltransferase critical for miRNA biogenesis (Baranauske et al. 2015). Plant miRNAs and siRNAs carry a 2'-O-methyl group on the 3'-terminal nucleotide, a modification introduced by HEN1 that protects small RNAs from enzymatic activities targeting the 3'-OH. In plants with no HEN1 activity, small RNAs accumulate at a lower level and present heterogeneous size (Yu et al. 2005). hen $1-8$ and hyll-2 ovules failed to grow asymmetric integuments, leading to defective embryo sac development; thus, it compromises pollen tube guidance, causing reduced fertility (Wei et al. 2020). Ectopic expression of ARF6 and ARF8 in hen 1-8 ovules was consistent with the reduction of miRNA167, whose processing relies on HEN1 (Yu et al. 2010). However, introducing the arf6 arf8 double mutant did not suppress ovule defects of hen $1-8$, suggesting the involvement of more microRNAs in this process, which may include miR165 and miR166 (Sakaguchi et al. 2012; Hashimoto et al. 2018).

Both miR165 and miR166 have been widely studied for their role in regulating the polarity of lateral organs. In particular, they contribute to the establishment of the abaxial/adaxial patterning of leaf primordia, through the silencing of their $H D$-ZIP III family targets, including PHABULOSA (PHB), PHAVOLUTA (PHV) and CORONA (CNA; Sakaguchi et al. 2012). $P H B, P H V$ and $C N A$ are expressed adaxially in the inner integument and loss of function of these genes or their overexpression leads to striking defects in integument formation (Kelley et al. 2009). Accordingly, miRI66D and MIRI66G, a subset of miR165/166 genes that are distinct from those acting in root and leaf, are highly expressed in ovule primordia, where they restrict the expression of $P H B$ in the apical region of the incipient inner integument (Hashimoto et al. 2018). miR166 shows non-cell-autonomous activity as its activity domain extends toward the ovule apex by a distance of one cell layer compared with the $m i R 166 D / G$ expression pattern (Hashimoto et al. 2018). In absence of miR166 function, PHB remains strongly expressed in the chalaza, resulting in compromised formation of the outer integuments. In a similar fashion, the miR165/166-insensitive $p h b-1 d /+$ mutant accumulates $p h b-l d$ transcripts in both integuments and arrests the outer integument growth (Sieber et al. 2004). Together, these results pointed out the importance of a precise balance between the relative levels of adaxial (HD-ZIP III) and abaxial (miR165/166) activities to support the correct growth of the two integuments (Fig. 4).

\section{Role of small RNAs in apomictic ovules}

Apomixis is asexual reproduction through seeds, a phenomenon that has evolved independently many times among angiosperms, with three families (Asteraceae, Poaceae and Rosaceae) most represented (Carman 1997). In addition, it is consistently associated with hybridity and polyploidy, but its origin and the underlying genetic mechanisms still represent an unsolved problem. There are generally two patterns of apomixis, depending on whether the embryo is developed from the unreduced female gametophyte (gametophytic apomixis) or directly from the nucellar cells (nucellar embryony; Fei et al. 2019). Since apomixis does not naturally occur in major crop species, its introduction into agronomically relevant plants would enable fixation of the complete genome of elite hybrid genotypes, leading to efficient and consistent production of high-quality grains, fruits and vegetables. Notwithstanding the importance of this process and the big effort invested in studying apomictic reproduction, many aspects of this reproductive strategy are yet to be fully understood (Hojsgaard and Hörandl 2019).

As already extensively discussed in the previous sections, several studies have indicated that small RNAs are involved in regulation of MMC specification and megasporogenesis, suggesting that they could be involved in the switch between sexual and asexual reproduction. In fact, Arabidopsis (including ago $, r d r 6, d r m 1$ and $d r m 2$ ) and maize (ago104, dmt102 and dmt103) mutants have been reported to show features resembling the initial steps of gametophytic apomixis (Olmedo-Monfil et al. 2010; Singh et al. 2011; Tucker et al. 2012; Zhai et al. 2014; Mendes et al. 2020). In order to identify potential pathways that could contribute to apomictic reproduction, several studies in the last decades have focused on high-throughput analysis of small RNAs. For instance, the study of Amiteye et al. (2011) constituted the first extensive insight into the conservation and expression of microRNAs in Boechera. In this genus, diplosporous apomeiosis leads to an unreduced embryo sac (Brukhin et al. 2019). In meiotic diplospory, the embryo sac originates from an MMC that undergoes an aberrant meiosis without recombination and chromosome reduction, resulting in the formation of a dyad of unreduced identical megaspores. Working with Boechera has several advantages: it has a relatively small genome, it is the only known diploid genus where apomixis has been described, and Boechera spp. are close relatives of the model plant Arabidopsis thaliana (Brukhin et al. 2019). Amiteye and collaborators (2011) identified 51 miRNA families in Boechera that are conserved in angiosperms. Among the targets of said miRNAs, the SQUAMOSA PROMOTER BINDING 11 (SPL11; target of 
miR156/157) has been reported to be up-regulated in the MMC of apomictic micro-dissected ovules. In Arabidopsis, SPL11 is highly expressed in inflorescences and it is associated with the transition from vegetative to reproductive phase (Shikata et al. 2009), but further investigations are required to dissect if SPL11 plays a role in apomictic reproduction.

With a similar approach, the role of miRNA-mRNA interactions has been investigated in the perennial grass Eragrostis curvula, providing sRNA libraries from apomictic and sexual genotypes (Garbus et al. 2019). E. curvula polyploids are facultative apomicts and reproduction occurs via diplosporous apomixis. Being adapted to sandy-soil and drought conditions, E. curvula represents an excellent forage source in semiarid climate regions, including in its native habitat in Africa. The analysis of Eragrostis curvula sRNA libraries, obtained from diplospory apomictic and sexual genotypes, lead to the identification of a number of miRNAs, belonging mainly to three families and differentially regulated in the two genetic backgrounds: miR2275 (which triggers the biogenesis of 24-nucleotide phased sRNAs), miR156 (which targets SPLs) and miR8175 (Garbus et al. 2019). The latter, miR8175, targets a TE, that was exclusively expressed in the apomictic accession. Interestingly, in several species, apomixis linked loci are chromosomal regions characterized by chromosomal rearrangements and accumulation of TEs. Associations between apospory and heterochromatic regions of the genome that are rich in retrotransposons raise the intriguing possibility that TEs might play a role in regulating expression of apomixis-related genes (Ochogavia et al., 2011, Kothani et al., 2014). Other two genes, differentially expressed during female reproductive development between apomictic and sexual plants in E. curvatula, were EcAGO104 and EcDMT102, encoding for proteins, whose implication in RdDM has already been reported (GarciaAguilar et al. 2010; Singh et al. 2011). These data are consistent with a role of said genes in apomixis; however, this provides no causal link as functional studies on mutants have not been carried out yet (Selva et al. 2017).

Initial characterization of small RNA pathways has also been undertaken in some apospory species, such as Hieracium, Paspalum and Hypericum spp. (summarized in Table 1). In aposporic apomixis, the unreduced embryo sacs develop from a nucellar cell adjacent to the MMC (please, see review of Hojsgaard and Hörandl 2019). Hieracium is a genus belonging to the Asteraceae family, with the appearance of small annual or perennial herbaceous plants and a typical inflorescence, similar to yellow daisies. Apomictic members of the Hieracium subgenus Pilosella are often polyploids and they are facultative apomicts, exhibiting apospory in combination with autonomous embryo and endosperm formation (Rabiger et al. 2016). In Hieracium pilosella, the whole ovary transcriptome from apomictic and mutant apomictic plants, which presented reversion to sexual reproduction, was compared (Rabiger et al. 2016). This study revealed that genes involved in small RNA biogenesis and chromatin silencing were differentially expressed in the two genotypes. Although eleven Hieracium pilosella AGO encoding genes were identified, the putative ortholog of AtAGO9 was not found, despite its role in restricting MMC specification reported in Arabidopsis (Olmedo-Monfil et al. 2010; Rabiger et al. 2016; Mendes et al. 2020).

New data related to apospory comes from studies in Paspalum notatum, an important forage crop native to South America, which includes sexual diploid and apomictic polyploid biotypes. Ortiz et al. (2019) identified in Paspalum notatum fifty-six clusters of miRNAs differentially represented in apomictic and sexual plants (up-regulated in apomictic), by combining available transcriptomic resources with small RNA-seq profiling. Interestingly, examination of the potential targets of these miRNAs pointed out an enrichment for genes involved in auxin pathways, from metabolism to signaling. For instance, miR160 and miR167, which regulate $A R F s$ expression, were differentially expressed in apomictic plants, suggesting that auxin network might be perturbed during ovule development in $P$. notatum biotypes (Ortiz et al. 2019). Moreover, a previous work in P. notatum, identified a long non-coding RNA (named $P N_{-} L N C \_N 13$ ), expressed only in natural apomictic tetraploid genotypes and not in artificially tetraploidized sexual genotypes (Laspina et al. 2008; Ochogavia et al. 2018). The sequence of the putative target of $P N_{-} L N C \_N 13$ was used to identify the most likely Arabidopsis orthologs and the best match was ARABIDOPSIS RESPONSE REGULATOR 9 (ARR9), involved in cytokinins response (Ochogavia et al. 2018).

Finally, small RNA-seq analysis has been performed also in citrus, one of the most commercially relevant fruit trees worldwide. Citrus is characterized by a nucellar embryony type of apomixis, where asexual embryos initiate directly from unreduced, somatic, nucellar cells surrounding the embryo sac. From a genome-wide association study (GWAS), a candidate gene for citrus polyembryony has been proposed (Wang et al. 2017). In addition, Long et al. (2016) identified 150 miRNAs in ovules immediately prior to and after nucellar embryony initiation, and among them miR23-5p showed negative correlation in expression with their target genes.

\section{Beyond Arabidopsis: the roles of small RNA pathways in ovule development in diverse plant species}

Knowledge about the role of small RNAs in ovule and female gametophyte development in other species is still expanding. Several experimental approaches, such as 
Table 1 Selection of high-throughput small RNA analyses performed on ovules and female reproductive tissues

\begin{tabular}{|c|c|c|}
\hline Species & Experimental approaches & References \\
\hline Asparagus officinalis & sRNA-seq, degrad. analysis & Chen et al. (2016) \\
\hline Boechera stricta & in-silico miRNAs ident. and targets pred. & Amiteye et al. (2011) \\
\hline Boechera stricta & sRNA microarray assay and misRNAs pred. & Amiteye et al. (2013) \\
\hline Brassica rapa & ncRNA ident. and description & Byeon et al. (2017) \\
\hline Brassica rapa & sRNA-seq, siRNA analysis, bisulfite sequencing & Grover et al. (2020) \\
\hline Chrysanthemum morifolium & sRNA-seq, miRNA analysis and targets pred. & Zhang et al. (2015) \\
\hline Cleistogenes songorica & sRNA-seq, miRNA analysis and targets pred. & Wu et al. (2018) \\
\hline Citrus spp. & sRNA-seq, miRNA analysis and targets pred. & Long et al. (2016) \\
\hline Corylus spp. & sRNA-seq, miRNA analysis and targets pred. & Liu et al. (2020a) \\
\hline Eragrostis curvula & sRNA-seq, miRNA analysis and targets pred. & Garbus et al. (2019) \\
\hline Ginkgo biloba & sRNA-seq, degrad. analysis, miRNA targets pred. & Liu et al. (2020b) \\
\hline Gossypium hirsutum & sRNA-seq & Abdurakhmonov et al. (2008) \\
\hline Gossypium hirsutum & sRNA-seq, miRNA analysis and targets pred. & Pang et al. 2009) \\
\hline Gossypium hirsutum & sRNA-seq, degrad. analysis, miRNA targets pred. & Liu et al. (2014) \\
\hline Gossypium hirsutum & sRNA-seq, methylC-seq & Song et al. (2015) \\
\hline Gossypium hirsutum & sRNA-seq, miRNA analysis and targets pred. & Xie et al. (2015) \\
\hline Gossypium hirsutum & sRNA-seq, miRNA analysis and targets pred. & Zhao et al. (2019) \\
\hline Hieracium spp. & sRNA-seq & Rabiger et al. (2016) \\
\hline Hypericum perforatum & in-silico miRNAs ident./targets pred. & Galla et al. (2013) \\
\hline Oryza sativa (autotetraploid) & sRNA-seq, miRNA targets pred. & Li et al. (2017) \\
\hline Oryza sativa & sRNA-seq, miRNA targets pred. & Yang et al. (2017) \\
\hline Oryza sativa & sRNA-seq, miRNA targets pred. & Wu et al. (2017) \\
\hline Oryza sativa & sRNA-seq, methylC-seq & Li et al. (2020a) \\
\hline Oryza sativa & ssRNA-seq and lncRNA ident. & Liu et al. (2019) \\
\hline Oryza sativa (autotetraploid) & lncRNAs ident. & Li et al. (2020b) \\
\hline Paspalum notatum & sRNA-seq, miRNA analysis and targets pred. & Ortiz et al. (2019) \\
\hline Pinus taeda & miRNA detection by RT-PCR & Oh et al. (2008) \\
\hline Punica granatum & sRNA-seq, miRNA analysis and targets pred. & Chen et al. (2020) \\
\hline
\end{tabular}

degrad. $=$ degradome; pred. $=$ prediction; ident. $=$ identification

sRNA and lncRNA sequencing, degradome analysis, and target prediction, were performed in ovule tissue samples of several flowering plant species other than Arabidopsis, as summarized in Table 1. These studies include ovule samples from agronomically important species including rice, cotton and Brassica rapa. Outside of angiosperms, the role of sRNAs in ovule development is underexplored. In gymnosperms, despite recent progress on sRNA profiles in male gametophytes, the contribution of sRNAs to ovule development remains to be understood. In fact, several studies revealed the presence of a pool of 24 nucleotide sRNAs in pollen, while only 21 nucleotide sRNAs have previously been detected in needles (Dolgosheina et al. 2008; Nakamura et al. 2019). More widely, it will be interesting to understand the role of small RNAs in female gametogenesis in the emerging model species Marchantia polymorpha (a liverwort) and Physcomitrella patens (a moss; Coruh et al. 2015; Bowman et al. 2017).
Several comprehensive analyses of sRNA expression in ovule development have been performed in rice. By including several stages of ovule development in a single rice cultivar, Wu et al. (2017) reported expression of 486 known miRNAs, and 204 novel miRNAs; their targets were then identified. Furthermore, integrated analysis with ovule transcriptome data enabled screening of possible miRNA targets that showed coherent expression levels with miRNAs in ovules (Wu et al. 2017). A similar approach was used to investigate the potential regulatory effects of miRNAs and lncRNAs on rice female gametophyte abortion, comparing the miRNA transcriptome in ovules of a high frequency female-sterile line $(f s v l)$ and a wild-type line (Gui 99) during ovule development (Yang et al. 2017; Liu et al. 2019). These studies identified 100 known miRNAs and around 500 lncRNAs that were significantly differentially expressed in $f s v 1$ compared to the wild-type (i.e., Gui 99); thus, it provides a pool 
of ncRNAs with a potential role in rice female gametophyte (Yang et al. 2017). One of the major barriers in commercial application of rice polyploids is their low fertility. It has been suggested that differential expression patterns of small RNAs during embryo sac development in autotetraploid rice might be associated with sterility (Li et al. 2017). Among the differentially expressed miRNAs, two of them were associated with female meiosis. Interestingly, their putative targets MINICHROMOSOME MAINTENANCE FAMILY 9 (MCM9) and REPLICATION PROTEIN A 2C (RPA2C) are known to be meiosis-related genes.

Furthermore, Li et al. (2017, 2020b) identified 24 nucleotide TE-derived siRNAs and lncRNAs, specifically expressed in autotetraploid rice ovules at MMC stage. The expression levels of several genes may change under the influence of TE derived siRNA triggered methylation, particularly at the crucial stages of female meiosis, which explained more than $95 \%$ up-regulated TE-derived siRNAs during the embryo sac development in autotetraploid rice (Li et al. 2017). Overall, the list of differentially expressed lncRNA during meiosis in rice ovaries will be beneficial for future studies in plant reproduction, in order to overcome sterility of polyploid rice.

$\mathrm{RdDM}$ mediated $\mathrm{CHH}$ hypermethylation has been reported in Gossypium hirsutum (cotton) ovules and ovulederived cotton fibers (Song et al. 2015). In cotton ovules $\mathrm{CHH}$ hypermethylation is found in $5^{\prime}$ of genes, while in ovule-derived cotton fibers this hypermethylation is enhanced, and CHH hypermethylation is also reported to be on TEs (Song et al. 2015). Genes preferentially expressed in ovules presented $5^{\prime}$ methylation, while this is not the case for genes preferentially expressed in leaves. Treatment of in vitro cultured cotton ovules with a DNA methyltransferase inhibitor, 5-aza-deoxycytidine, leads to reduced cotton fiber length, suggesting that DNA methylation might play a role in cotton fiber development. In the future, the precise modulation of RdDM in cotton ovules and developing cotton fibers would be required to show a causal link between them.

An important role for small RNAs and RdDM has also been established in the crop species Brassica rapa (Grover et al. 2018; 2020). Through conventional hybridization, it has been shown that high rates of seed abortion are found from RdDM mutant mothers, but not from RdDM mutant fathers (Grover et al. 2018). This analysis showed that RdDM activity is required in $B$. rapa maternal sporophytic tissue, and not in the female gametophyte for successful seed development (Grover et al. 2018). Small RNAs are highly abundant during female reproductive development in $B$. rapa, and the majority of small RNAs originate from a small number of loci (Grover et al. 2020): these siren siRNAs are present in ovules, seed coats, embryos and endosperm (Grover et al. 2020). RDR2 is essential for the production of siren siRNAs in the maternal sporophyte and the maternal genotype also dictates whether they accumulate in later tissues, suggesting the deposition of maternal siRNAs is important for normal seed development in B. rapa.

\section{Conclusion and future perspectives}

Since the discovery of small RNAs in plants (Hamilton and Balucombe 1999), the diversity of plant small RNA biogenesis and function has been gradually revealed, yet the full complexity and inter-relatedness of the pathways is still being explored (Cuerda-Gil and Slotkin 2016). Here, we focused on the role of small RNAs during ovule development, where they appear to play a role in germline specification, megagametogenesis and integument development. Despite significant progress on this topic in recent years, the combination of genetic redundancy of small RNA biogenesis and effector pathways, and the embryo lethality of some Arabidopsis small RNA mutants mean that further genetic dissection will likely remain a challenge.

In wild-type sexual species, the number of MMCs within a single ovule is restricted to one. In various Arabidopsis small RNA mutants, additional MMC-like cells are observed. The classic RdDM DNA methyltransferase double mutant $d r m 1$ drm 2 also has additional MMCs (Mendes et al. 2020). Intriguingly, RDR6 was initially found to be an important part of the co-suppression pathway in the plant immune system (Dalmay et al. 2000; Mourrain et al. 2000). Later, it was shown to play a key role in ta-siRNA biosynthesis (Yoshikawa et al. 2005) and a minor role in RdDM in somatic tissues (Stroud et al. 2013). RDR6 is clearly a "pleiotropic actor" in small RNA biogenesis and exemplifies the complexity of plant small RNA pathways; also, it suggests that attributing labels of distinct pathways to genes is sometimes misleading. Within the RdDM field, discussion continues over the role of "canonical" and "non-canonical RdDM" pathways that may occur in parallel within a single cell or play a specific role in specific cell types (Cuerda-Gil and Slotkin 2016). In the future, it will be interesting to further explore whether the small RNA mutants that give rise to additional MMCs are due to separate small RNA pathways ("canonical" RdDM and ta-siRNAs) or if they could contribute to a "non-canonical" RdDM pathway. Interestingly, Su and collaborators (2017) showed that mutation in texl enhanced the $r d r 6$ phenotype, suggesting that two parallel pathways might synergically act in female germline fate. Highlighting the complexity of small RNA biology within ovules, all ten known AGO proteins have been detected during female reproduction in Arabidopsis (Jullien et al. 2020). Further to this, it has already been shown that AGO4, AGO6 and AGO8 may also contribute to MMC number specification; interestingly, in ago4 ago 9 double mutants AGO6 
expression is increased to likely compensate for lack of AGO4 and AGO9 (Hernández-Lagana et al. 2016). The use of cell type specific approaches, including scRNA-seq and conditional CRISPR/Cas9 genome editing, may represent the best route to furthering our understanding of MMC specification by small RNA pathways.

To date, most functional studies of small RNA pathways in ovule development have focused on Arabidopsis, along with notable contributions in rice and maize. In numerous other species, ovule enriched small RNAs have been characterized by next generation sequencing (summarized in Table 1) and have therefore been largely descriptive. In future, we expect that functional genetic studies in diverse plant species, powered by CRISPR/Cas9 gene editing and using an evolutionary developmental biology approach, will enrich our understanding of the role of small RNAs in ovule development.

Acknowledgements We thank Professor Martin Kater and James Friel for critically revisiting the manuscript. We apologize to all the researchers whose work could not be cited due to space limitations.

Author contribution statement R.P. conceived and wrote the manuscript, performed the literature search and developed the figures, M.C. performed the literature search and wrote some sections, M.A.M. and C.U. wrote some sections of the manuscript and critically revised earlier versions, L.C. conceived and critically revised the manuscript.

Funding Open access funding provided by Università degli Studi di Milano within the CRUI-CARE Agreement. C. U. is supported by the Max Planck Society, R.P, M.C and L.C is supported by KeyGene N.V and EXPOSEED H2020-MSCA-RISE-2015, M.A.M is supported by Linea 2 Università degli Studi di Milano-PSR2015-1719LCOLO_11.

\section{Declarations}

Conflict of interest The authors have no conflicts of interest to declare that are relevant to the content of this article.

Open Access This article is licensed under a Creative Commons Attribution 4.0 International License, which permits use, sharing, adaptation, distribution and reproduction in any medium or format, as long as you give appropriate credit to the original author(s) and the source, provide a link to the Creative Commons licence, and indicate if changes were made. The images or other third party material in this article are included in the article's Creative Commons licence, unless indicated otherwise in a credit line to the material. If material is not included in the article's Creative Commons licence and your intended use is not permitted by statutory regulation or exceeds the permitted use, you will need to obtain permission directly from the copyright holder. To view a copy of this licence, visit http://creativecommons.org/licenses/by/4.0/.

\section{References}

Abdurakhmonov IY, Devor EJ, Buriev ZT, Huang L, Makamov A, Shermatov SE, Bozorov T, Kushanov FN, Mavlonov GT, Abdukarimov A (2008) Small RNA regulation of ovule development in the cotton plant G Hirsutum 1. BMC Plant Biol 8:93. https:// doi.org/10.1186/1471-2229-8-93

Amiteye S, Corral JM, Vogel H, Sharbel TF (2011) Analysis of conserved microRNAs in floral tissues of sexual and apomictic Boechera species. BMC Genomics 11(12):500. https://doi.org/ 10.1186/1471-2164-12-500

Amiteye S, Corral JM, Vogel H, Kuhlmann M, Mette MF, Sharbel TF (2013) Novel microRNAs and microsatellite-like small RNAs in sexual and apomictic Boechera species. Microrna 2(1):45-62

Araki S, Le NT, Koizumi K, Villar-Briones A, Nonomura KI, Endo M, Inoue H, Saze H, Komiya R (2020) miR2118-dependent U-rich phasiRNA production in rice anther wall development. Nat Commun 11(1):3115. https://doi.org/10.1038/s41467-020-16637-3

Arteaga-Vázquez M, Caballero-Pérez J, Vielle-Calzada JP (2006) A family of microRNAs present in plants and animals. Plant Cell 18(12):3355-3369. https://doi.org/10.1105/tpc.106.044420

Baranauske S, Mickute M, Plotnikova A, Finke A, Venclovas C, Klimasauskas $S$ et al (2015) Functional mapping of the plant small RNA methyltransferase: HEN1 physically interacts with HYL1 and DICER-LIKE 1 proteins. Nucleic Acids Res 43:2802-2812. https://doi.org/10.1093/nar/gkv102

Bencivenga S, Colombo L, Masiero S (2011) Cross talk between the sporophyte and the megagametophyte during ovule development. Sex Plant Reprod 24(2):113-121. https://doi.org/10.1007/ s00497-011-0162-3

Bencivenga S, Simonini S, Benková E, Colombo L (2012) The transcription factors BEL1 and SPL are required for cytokinin and auxin signaling during Ovule Development in arabidopsis. Plant Cell 24(7):2886-2897. https://doi.org/10.1105/tpc.112.100164

Bologna NG, Iselin R, Abriata LA, Sarazin A, Pumplin N, Jay F, Grentzinger T, Dal Peraro M, Voinnet O (2018) Nucleo-cytosolic shuttling of ARGONAUTE1 prompts a revised model of the plant microRNA pathway. Mol Cell 69(4):709-719.e5. https:// doi.org/10.1016/j.molcel.2018.01.007

Borges F, Martienssen RA (2015) The expanding world of small RNAs in plants. Nat Rev Mol Cell Biol 16(12):727-741. https://doi.org/ 10.1038/nrm4085

Bowman JL, Kohchi T, Yamato KT, Jenkins J, Shu S, Ishizaki K, Yamaoka S, Nishihama R, Nakamura Y, Berger F et al (2017) Insights into land plant evolution garnered from the marchantia polymorpha genome. Cell 171(2):287-304.e15. https://doi.org/ 10.1016/j.cell.2017.09.030

Brukhin V, Osadtchiy JV, Florez-Rueda AM, Smetanin D, Bakin E, Nobre MS, Grossniklaus U (2019) The Boechera Genus as a resource for apomixis research. Front Plant Sci 2(10):392. https:// doi.org/10.3389/fpls.2019.00392

Byeon B, Bilichak A, Kovalchuk I (2017) Computational characterization of ncRNA fragments in various tissues of the Brassica rapa. Plant Noncoding RNA 3(2):17. https://doi.org/10.3390/ ncrna3020017

Carman JG (1997) Asynchronous expression of duplicate genes in angiosperms may cause apomixis, bispory, tetraspory, and polyembryony. Biol J Linn Soc 61:51-94

Chen J, Zheng Y, Qin L, Wang Y, Chen L, He Y, Fei Z, Lu G (2016) Ident. of miRNAs and their targets through high-throughput sequencing and degradome analysis in male and female Asparagus officinalis. BMC Plant Biol 16:80. https://doi.org/10.1186/ s12870-016-0770-Z

Chen L, Luo X, Yang X, Jing D, Xia X, Li H, Poudel K, Cao S (2020) Small RNA and mRNA sequencing reveal the roles of 
microRNAs involved in pomegranate female sterility. Int J Mol Sci 21(2):558. https://doi.org/10.3390/ijms21020558

Coruh C, Cho SH, Shahid S, Liu Q, Wierzbicki A, Axtell MJ (2015) Comprehensive annotation of physcomitrella patens small RNA Loci reveals that the heterochromatic short interfering RNA pathway is largely conserved in land plants. Plant Cell 27(8):21482162. https://doi.org/10.1105/tpc.15.00228

Cuerda-Gil D, Slotkin RK (2016) Non-canonical RNA-directed DNA methylation. Nat Plants 2(11):16163. https://doi.org/10.1038/ nplants.2016.163

Dai X, Zhuang Z, Zhao PX (2018) psRNATarget: a plant small RNA target analysis server. Nucleic Acids. Res 46(W1):W49-W54. https://doi.org/10.1093/nar/gky316

Dalmay T, Hamilton A, Rudd S, Angell S, Baulcombe DC (2000) An RNA-dependent RNA polymerase gene in arabidopsis is required for posttranscriptional gene silencing mediated by a transgene but not by a virus. Cell 101(5):543-553. https://doi.org/10.1016/ s0092-8674(00)80864-8

Deng P, Muhammad S, Cao M, Wu L (2018) Biogenesis and regulatory hierarchy of phased small interfering RNAs in plants. Plant Biotechnol J 16(5):965-975. https://doi.org/10.1111/pbi.12882

Dolgosheina EV, Morin RD, Aksay G, Sahinalp SC, Magrini V, Mardis ER, Mattsson J, Unrau PJ (2008) Conifers have a unique small RNA silencing signature. RNA 14(8):1508-1515. https://doi.org/ 10.1261/rna.1052008

Drews GN, Koltunow AM (2011) The female gametophyte. Arabidopsis Book 9:e0155. https://doi.org/10.1199/tab.0155

Fahlgren N, Montgomery TA, Howell MD, Allen E, Dvorak SK, Alexander AL, Carrington JC (2006) Regulation of AUXIN RESPONSE FACTOR3 ta-siRNA affects developmental timing and patterning in Arabidopsis. Curr Biol 16(9):939-44. https:// doi.org/10.1016/j.cub.2006.03.065

Favaro R, Pinyopich A, Battaglia R, Kooiker M, Borghi L, Ditta G, Yanofsky MF, Kater MM, Colombo L (2003) MADS-box protein complexes control carpel and ovule development in arabidopsis. Plant Cell 15(11):2603-2611. https://doi.org/10.1105/tpc.015123

Fei X, Shi J, Liu Y, Niu J, Wei A (2019) The steps from sexual reproduction to apomixis. Planta 249(6):1715-1730. https://doi.org/ 10.1007/s00425-019-03113-6

Francisco-Mangilet AG, Karlsson P, Kim MH, Eo HJ, Oh SA, Kim JH, Kulcheski FR, Park SK, Manavella PA (2015) THO2, a core member of the THO/TREX complex, is required for microRNA production in Arabidopsis. Plant J 82(6):1018-1029. https://doi. org/10.1111/tpj.12874

Fukudome A, Fukuhara T (2017) Plant dicer-like proteins: double-stranded RNA-cleaving enzymes for small RNA biogenesis. J Plant Res 130(1):33-44. https://doi.org/10.1007/ s10265-016-0877-1

Galla G, Volpato M, Sharbel TF, Barcaccia G (2013) Computational identification of conserved microRNAs and their putative targets in the hypericum perforatum L. flower transcriptome. Plant Reprod 26(3):209-29. https://doi.org/10.1007/ s00497-013-0227-6

Garbus I, Selva JP, Pasten MC, Bellido AM, Carballo J, Albertini E, Echenique V (2019) Characterization and discovery of miRNA and miRNA targets from apomictic and sexual genotypes of Eragrostis curvula. BMC Genomics 20(1):839. https://doi.org/10. 1186/s12864-019-6169-0

Garcia-Aguilar M, Michaud C, Leblanc O, Grimanelli D (2010) Inactivation of a DNA methylation pathway in maize reproductive organs results in apomixis-like phenotypes. Plant Cell 22(10):3249-3267. https://doi.org/10.1105/tpc.109.072181

Gasser CS, Skinner DJ (2018) Development and evolution of the unique ovules of flowering plants. Curr Top Dev Biol 131:373399. https://doi.org/10.1016/bs.ctdb.2018.10.007
Groß-Hardt R, Laux T (2003) Stem cell regulation in the shoot meristem. J Cell Sci 116(Pt 9):1659-66. https://doi.org/10.1242/jcs. 00406

Grover JW, Kendall T, Baten A, Burgess D, Freeling M, King GJ, Mosher RA (2018) Maternal components of RNA-directed DNA methylation are required for seed development in Brassica rapa. Plant J 94(4):575-582. https://doi.org/10.1111/tpj.13910 (Epub 2018 Apr 23. PMID: 29569777)

Grover JW, Burgess D, Kendall T, Baten A, Pokhrel S, King GJ, Meyers BC, Freeling M, Mosher RA (2020) Abundant expression of maternal siRNAs is a conserved feature of seed development. Proc Natl Acad Sci U S A 117(26):15305-15315. https://doi. org/10.1073/pnas.2001332117

Gustafson EA, Wessel GM (2010) Vasa genes: emerging roles in the germ line and in multipotent cells. BioEssays 32(7):626-637. https://doi.org/10.1002/bies.201000001

Hamilton AJ, Baulcombe DC (1999) A species of small antisense RNA in posttranscriptional gene silencing in plants. Science 286(5441):950-2. https://doi.org/10.1126/science.286.5441.950

Hashimoto K, Miyashima S, Sato-Nara K, Yamada T, Nakajima K (2018) Functionally diversified members of the MIR165/6 Gene family regulate Ovule morphogenesis in arabidopsis thaliana. Plant Cell Physiol 59(5):1017-1026. https://doi.org/10.1093/ $\mathrm{pcp} / \mathrm{pcy} 042$

Hater F, Nakel T, Groß-Hardt R (2020) Reproductive multitasking: the female gametophyte. Annu Rev Plant Biol. 71:517-546. https:// doi.org/10.1146/annurev-arplant-081519-035943

Havecker ER, Wallbridge LM, Hardcastle TJ, Bush MS, Kelly KA, Dunn RM, Schwach F, Doonan JH, Baulcombe DC (2010) The Arabidopsis RNA-directed DNA methylation argonautes functionally diverge based on their expression and interaction with target loci. Plant Cell 22(2):321-334. https://doi.org/10.1105/ tpc.109.072199

Hernández Lagana E, Rodríguez Leal D, Lúa J, Vielle Calzada JP (2016) A multigenic network ARGONAUTE4 of clade members controls early megaspore formation in Arabidopsis. Genetics 204(3):1045-1056. https://doi.org/10.1534/genetics.116.188151

Hojsgaard D, Hörandl E (2019) The rise of apomixis in natural plant populations. Front Plant Sci 2(10):358. https://doi.org/10.3389/ fpls.2019.00358

Houwing S, Berezikov E, Ketting RF (2008) Zili is required for germ cell differentiation and meiosis in zebrafish. EMBO J 27(20):2702-2711. https://doi.org/10.1038/emboj.2008.204

Jauvion V, Elmayan T, Vaucheret H (2010) The conserved RNA trafficking proteins HPR1 and TEX1 are involved in the production of endogenous and exogenous small interfering RNA in Arabidopsis. Plant cell 22(8):2697-2709. https://doi.org/10.1105/tpc. 110.076638

Jullien PE, Grob S, Marchais A, Pumplin N, Chevalier C, Bonnet DMV, Otto C, Schott G, Voinnet O (2020) Functional characterization of Arabidopsis ARGONAUTE 3 in reproductive tissues. Plant $\mathbf{J}$ 103(5):1796-1809. https://doi.org/10.1111/tpj.14868

Kasschau KD, Xie Z, Allen E, Llave C, Chapman EJ, Krizan KA, Carrington JC (2003) P1/HC-Pro, a viral suppressor of RNA silencing, interferes with Arabidopsis development and miRNA function. Dev Cell 4:205-217. https://doi.org/10.1016/s15345807(03)00025-X

Kelley DR, Skinner DJ, Gasser CS (2009) Roles of polarity determinants in ovule development. Plant J 57(6):1054-1064. https:// doi.org/10.1111/j.1365-313X.2008.03752.x

Komiya R, Ohyanagi H, Niihama M, Watanabe T, Nakano M, Kurata N, Nonomura K (2014) Rice germline-specific Argonaute MEL1 protein binds to phasiRNAs generated from more than 700 lincRNAs. Plant J 78(3):385-397. https://doi.org/10.1111/tpj.12483

Kumakura N, Takeda A, Fujioka Y, Motose H, Takano R, Watanabe Y (2009) SGS3 and RDR6 interact and colocalize in cytoplasmic 
SGS3/RDR6-bodies. FEBS Lett 583(8):1261-6. https://doi.org/ 10.1016/j.febslet.2009.03.055

Kurihara Y, Takashi Y, Watanabe Y (2006) The interaction between DCL1 and HYL1 is important for efficient and precise processing of pri-miRNA in plant microRNA biogenesis. RNA 12:206-212. https://doi.org/10.1261/rna.2146906

Lang JD, Ray S, Ray A (1994) Sin 1, a mutation affecting female fertility in Arabidopsis, interacts with mod 1, its recessive modifier. Genetics 137(4):1101-1110

Laspina NV, Vega T, Seijo JG, González AM, Martelotto LG, Stein J, Podio M, Ortiz JP, Echenique VC, Quarin CL, Pessino SC (2008) Gene expression analysis at the onset of aposporous apomixis in Paspalum notatum. Plant Mol Biol 67(6):615-628. https://doi. org/10.1007/s11103-008-9341-5

Law JA, Jacobsen SE (2010) Establishing, maintaining and modifying DNA methylation patterns in plants and animals. Nat Rev Genet 11:204-220. https://doi.org/10.1038/nrg2719

Li X, Shahid MQ, Xia J, Lu Z, Fang N, Wang L, Wu J, Chen Z, Liu $X$ (2017) Analysis of small RNAs revealed differential expressions during pollen and embryo sac development in autotetraploid rice. BMC Genomics 18(1):129. https://doi.org/10.1186/ s12864-017-3526-8

Li C, Xu H, Fu FF, Russell SD, Sundaresan V, Gent JI (2020a) Genome-wide redistribution of 24-nt siRNAs in rice gametes. Genome Res 30(2):173-184. https://doi.org/10.1101/gr.253674. 119

Li X, Shahid MQ, Wen M, Chen S, Yu H, Jiao Y, Lu Z, Li Y, Liu X (2020b) Global identification and analysis revealed differentially expressed lncRNAs associated with meiosis and low fertility in autotetraploid rice. BMC Plant Biol 20(1):82. https://doi.org/10. 1186/s12870-020-2290-0

Liu N, Tu L, Tang W, Gao W, Lindsey K, Zhang X (2014) Small RNA and degradome profiling reveals a role for miRNAs and their targets in the developing fibers of Gossypium barbadense. Plant J 80(2):331-344. https://doi.org/10.1111/tpj.12636

Liu C, Xin Y, Xu L, Cai Z, Xue Y, Liu Y, Xie D, Liu Y, Qi Y (2018) Arabidopsis ARGONAUTE 1 binds chromatin to promote gene transcription in response to hormones and stresses. Dev Cell 44(3):348-361.e7. https://doi.org/10.1016/j.devcel.2017.12.002

Liu H, Wang R, Mao B, Zhao B, Wang J (2019) Identification of lncRNAs involved in rice ovule development and female gametophyte abortion by genome-wide screening and functional analysis. BMC Genomics 20(1):90. https://doi.org/10.1186/ s12864-019-5442-6

Liu J, Luo Q, Zhang X, Zhang Q, Cheng Y (2020a) Ident of vital candidate microRNA/mRNA pairs regulating ovule development using high-throughput sequencing in hazel. BMC Dev Biol 20(1):13. https://doi.org/10.1186/s12861-020-00219-Z

Liu XM, Cheng SY, Ye JB, Chen ZX, Liao YL, Zhang WW, Kim SU, $\mathrm{Xu} F(2020 \mathrm{~b})$ Screening and ident. of miRNAs related to sexual differentiation of strobili in Ginkgo biloba by integration analysis of small RNA, RNA, and degradome sequencing. BMC Plant Biol 20(1):387. https://doi.org/10.1186/s12870-020-02598-8

Long JM, Liu Z, Wu XM, Fang YN, Jia HH, Xie ZZ, Deng XX, Guo WW (2016) Genome-scale mRNA and small RNA transcriptomic insights into initiation of citrus apomixis. J Exp Bot 67(19):5743-5756. https://doi.org/10.1093/jxb/erw338

Masuda S, Das R, Cheng H, Hurt E, Dorman N, Reed R (2005) Recruitment of the human TREX complex to mRNA during splicing. Genes Dev 19(13):1512-7. https://doi.org/10.1101/gad.1302205

Matzke MA, Mosher RA (2014) RNA-directed DNA methylation: an epigenetic pathway of increasing complexity. Nat Rev Genet 15(6):394-408. https://doi.org/10.1038/nrg3683

Mendes MA, Petrella R, Cucinotta M, Vignati E, Gatti S, Pinto SC, Bird DC, Gregis V, Dickinson Hugh, Tucker MR, Colombo
L (2020) The RNA-dependent DNA methylation pathway is required to restrict SPOROCYTELESS/NOZZLE expression to specify a single female germ cell precursor in Arabidopsis. Dev 147:194274. https://doi.org/10.1242/dev.194274

Montgomery TA, Howell MD, Cuperus JT, Li D, Hansen JE, Alexander AL, Chapman EJ, Fahlgren N, Allen E, Carrington JC (2008) Specificity of ARGONAUTE7-miR390 interaction and dual functionality in TAS3 trans-acting siRNA formation. Cell 133(1):128-41. https://doi.org/10.1016/j.cell.2008.02.033

Mourrain P, Béclin C, Elmayan T, Feuerbach F, Godon C, Morel JB, Jouette D, Lacombe AM, Nikic S, Picault N, Rémoué K, Sanial M, Vo TA, Vaucheret H (2000) Arabidopsis SGS2 and SGS3 genes are required for posttranscriptional gene silencing and natural virus resistance. Cell 101(5):533-42. https://doi.org/10. 1016/s0092-8674(00)80863-6

Nakamura M, Köhler C, Hennig L (2019) Tissue-specific transposon-associated small RNAs in the gymnosperm tree Norway Spruce . BMC Genomics 20:997. https://doi.org/10.1186/ s12864-019-6385-7

Nonomura KI, Morohoshi A, Nakano M, Eiguchi M, Miyao A, Hirochika H, Kurata N (2007) A germ cell-specific gene of the ARGONAUTE family is essential for the progression of premeiotic mitosis and meiosis during sporogenesis in rice. Plant Cell 9(8):2583-2594. https://doi.org/10.1105/tpc.107.053199

Ochogavía AC, Seijo JG, González AM, Podio M, Silveira ED, Lacerda ALM, de Campos T, Carneiro V, Pablo J, Ortiz A, Pessino SC (2011) Characterization of retrotransposon sequences expressed in inflorescences of apomictic and sexual Paspalum notatum plants. Sex Plant Reprod 24:231-246. https://doi.org/10.1007/ s00497-011-0165-0

Ochogavía A, Galla G, Seijo JG, González AM, Bellucci M, Pupilli F, Barcaccia G, Albertini E, Pessino S (2018) Structure, targetspecificity and expression of PN_LNC_N13, a long non-coding RNA differentially expressed in apomictic and sexual Paspalum notatum. Plant Mol Biol 96(1-2):53-67. https://doi.org/10.1007/ s11103-017-0679-4

Oh TJ, Wartell RM, Cairney J, Pullman GS (2008) Evidence for stage-specific modulation of specific microRNAs (miRNAs) and miRNA processing components in zygotic embryo and female gametophyte of loblolly pine (Pinus taeda). New Phytol 179(1):67-80. https://doi.org/10.1111/j.1469-8137.2008.02448.x

Oliver C, Santos JL, Pradillo M (2014) On the role of some ARGONAUTE proteins in meiosis and DNA repair in Arabidopsis thaliana. Front Plant Sci 5:177. https://doi.org/10.3389/fpls. 2014.00177

Oliver C, Pradillo M, Jover-Gil S, Cuñado N, Ponce MR, Santos JL (2017) Loss of function of Arabidopsis microRNA-machinery genes impairs fertility, and has effects on homologous recombination and meiotic chromatin dynamics. Sci Rep 7(1):9280. https://doi.org/10.1038/s41598-017-07702-x

Olivier M, Da Ines O, Amiard S, Serra H, Goubely C, White CI, Gallego ME (2015) The structure-specific endonucleases MUS81 and SEND1 are essential for telomere stability in Arabidopsis. Plant Cell 28(1):74-86. https://doi.org/10.1105/tpc.15.00898

Olmedo-Monfil V, Durán-Figueroa N, Arteaga-Vázquez M, DemesaArévalo E, Autran D, Grimanelli D, Slotkin RK, Martienssen RA, Vielle-Calzada JP (2010) Control of female gamete formation by a small RNA pathway in Arabidopsis. Nature 464(7288):628-32. https://doi.org/10.1038/nature08828

Ortiz JPA, Leblanc O, Rohr C, Grisolia M, Siena LA, Podio M, Colono C, Azzaro C, Pessino SC (2019) Small RNA-seq reveals novel regulatory components for apomixis in Paspalum notatum. BMC Genomics 20(1):487. https://doi.org/10.1186/s12864-019-5881-0

Pang M, Woodward AW, Agarwal V, Guan X, Ha M, Ramachandran V, Chen X, Triplett BA, Stelly DM, Chen ZJ (2009) Genome-wide 
analysis reveals rapid and dynamic changes in miRNA and siRNA sequence and expression during ovule and fiber development in allotetraploid cotton (Gossypium hirsutum L.). Genome Biol 10(11):R122. https://doi.org/10.1186/gb-2009-10-11-r122

Pinto SC, Mendes MA, Coimbra S, Tucker MR (2019) Revisiting the female germline and its expanding toolbox. Trends Plant Sci 24(5):455-467. https://doi.org/10.1016/j.tplants

Pinyopich A, Ditta GS, Savidge B, Liljegren SJ, Baumann E, Wisman E, Yanofsky MF (2003) Assessing the redundancy of MADS-box genes during carpel and ovule development. Nature 424(6944):85-8. https://doi.org/10.1038/nature01741

Rabiger DS, Taylor JM, Spriggs A, Hand ML, Henderson ST, Johnson SD, Oelkers K, Hrmova M, Saito K, Suzuki G, Mukai Y, Carroll BJ, Koltunow AM (2016) Generation of an integrated Hieracium genomic and transcriptomic resource enables exploration of small RNA pathways during apomixis initiation. BMC Biol 14(1):86. https://doi.org/10.1186/s12915-016-0311-0

Ray A, Lang JD, Golden T, Ray S (1996) SHORT INTEGUMENT (SIN1), a gene required for ovule development in Arabidopsis, also controls flowering time. Dev 122(9):2631-2638

Ren L, Tang D, Zhao T, Zhang F, Liu C, Xue Z, Shi W, Du G, Shen Y, Li Y, Cheng Z (2018) OsSPL regulates meiotic fate acquisition in rice. New Phytol 218(2):789-803. https://doi.org/10.1111/ nph. 15017

Robinson-Beers K, Pruitt RE, Gasser CS (1992) Ovule development in wild-type Arabidopsis and two female-sterile mutants. Plant Cell 4(10):1237-1249. https://doi.org/10.1105/tpc.4.10.1237

Rodríguez-Leal D, León-Martínez G, Abad-Vivero U, Vielle-Calzada JP (2015) Natural variation in epigenetic pathways affects the specification of female gamete precursors in Arabidopsis. Plant Cell 27(4):1034-1045. https://doi.org/10.1105/tpc.114.133009

Sakaguchi J, Watanabe Y (2012) miR165/166 and the development of land plants. Dev Growth Differ 54(1):93-99. https://doi.org/10. 1111/j.1440-169x.2011.01318.x

Schauer SE, Jacobsen SE, Meinke DW, Ray A (2002) DICER-LIKE1: blind men and elephants in Arabidopsis development. Trends Plant Sci 7(11):487-491. https://doi.org/10.1016/s1360-1385(02) 02355-5

Schiefthaler U, Balasubramanian S, Sieber P, Chevalier D, Wisman E, Schneitz K (1999) Molecular analysis of NOZZLE, a gene involved in pattern formation and early sporogenesis during sex organ development in Arabidopsis thaliana. Proc Natl Acad Sci USA 96:11664-11669. https://doi.org/10.1073/pnas.96.20.11664

Schmidt A, Wuest SE, Vijverberg K, Baroux C, Kleen D, Grossniklaus U (2011) Transcriptome analysis of the Arabidopsis megaspore mother cell uncovers the importance of RNA helicases for plant germline development. PLoS Biol 9(9):e1001155. https://doi.org/ 10.1371/journal.pbio.1001155

Selva JP, Siena L, Rodrigo JM, Garbus I, Zappacosta D, Romero JR, Ortiz JPA, Pessino SC, Leblanc O, Echenique V (2017) Temporal and spatial expression of genes involved in DNA methylation during reproductive development of sexual and apomictic Eragrostis curvula. Sci Rep 7(1):15092. https://doi.org/10.1038/ s41598-017-14898-5

Shikata M, Koyama T, Mitsuda N, Ohme-Takagi M (2009) Arabidopsis SBP-box genes SPL10, SPL11 and SPL2 control morphological change in association with shoot maturation in the reproductive phase. Plant Cell Physiol 50(12):2133-2145. https://doi.org/10. 1093/pcp/pcp148

Sieber P, Gheyselinck J, Gross-Hardt R, Laux T, Grossniklaus U, Schneitz K (2004) Pattern formation during early ovule development in Arabidopsis thaliana. Dev Biol 273(2):321-34. https://doi.org/ 10.1016/j.ydbio.2004.05.037

Singh M, Goel S, Meeley RB, Dantec C, Parrinello H, Michaud C, Leblanc O, Grimanelli D (2011) Production of viable gametes without meiosis in maize deficient for an ARGONAUTE protein. Plant Cell 23(2):443-458. https://doi.org/10.1105/tpc. 110.079020

Song Q, Guan X, Chen ZJ (2015) Dynamic roles for small RNAs and DNA methylation during Ovule and fiber development in allotetraploid cotton. PLoS Genet 11(12):e1005724. https:// doi.org/10.1371/journal.pgen.1005724

Sprunck S, Urban M, Strieder N, Lindemeier M, Bleckmann A, Evers M, Hackenberg T, Möhle C, Dresselhaus T, Engelmann JC (2019) Elucidating small RNA pathways in Arabidopsis thaliana egg cells. bioRxiv 525956. Doi: https://doi.org/10.1101/ 525956

Stroud H, Greenberg MV, Feng S, Bernatavichute YV, Jacobsen SE (2013) Comprehensive analysis of silencing mutants reveals complex regulation of the Arabidopsis methylome. Cell 152(12):352-64. https://doi.org/10.1016/j.cell.2012.10.054

Su Z, Zhao L, Zhao Y, Li S, Won S, Cai H, Wang L, Li Z, Chen P, Qin Y, Chen X (2017) The THO complex non-cell-autonomously represses female germline specification through the TAS3-ARF3 module. Curr Biol 27(11):1597-1609. https://doi. org/10.1016/j.cub.2017.05.021

Su Z, Wang N, Hou Z, Li B, Li D, Liu Y, Cai H, Qin Y, Chen X (2020) Regulation of female germline specification via small RNA mobility in Arabidopsis. Plant Cell 32(9):2842-2854. https://doi.org/10.1105/tpc.20.00126

Tucker MR, Okada T, Hu Y, Scholefield A, Taylor JM, Koltunow AM (2012) Somatic small RNA pathways promote the mitotic events of megagametogenesis during female reproductive development in Arabidopsis. Dev 139(8):1399-1404. https:// doi.org/10.1242/dev.075390

Vaucheret H (2008) Plant ARGONAUTES. Trends Plant Sci 13(7):350-358. https://doi.org/10.1016/j.tplants.2008.04.007

Volpe TA, Kidner C, Hall IM, Teng G, Grewal SI, Martienssen RA (2002) Regulation of heterochromatic silencing and histone H3 lysine-9 methylation by RNAi. Science 297(5588):1833-7. https://doi.org/10.1126/science.1074973

Wang X, Xu Y, Zhang S, Cao L, Huang Y, Cheng J, Wu G, Tian S, Chen C, Liu Y et al (2017) Genomic analyses of primitive, wild and cultivated citrus provide insights into asexual reproduction. Nat Genet 49(5):765-772. https://doi.org/10. 1038/ng.3839

Wang J, Mei J, Ren G (2019) Plant microRNAs: biogenesis, homeostasis, and degradation. Front Plant Sci 27(10):360. https://doi. org/10.3389/fpls.2019.00360

Wei SJ, Chai S, Zhu RM, Duan CY, Zhang Y, Li S (2020) HUA ENHANCER1 mediates Ovule development. Front Plant Sci 15(11):397. https://doi.org/10.3389/fpls.2020.00397

Willemse MTM (1992) Megasporogenesis and Megagametogenesis. Sex Plant Reprod. https://doi.org/10.1007/ 978-3-642-77677-9_5

Wu MF, Tian Q, Reed JW (2006) Arabidopsis microRNA167 controls patterns of ARF6 and ARF8 expression, and regulates both female and male reproduction. Dev 133(21):4211-4218. https:// doi.org/10.1242/dev.02602

Wu Y, Yang L, Yu M, Wang J (2017) Identification and expression analysis of microRNAs during ovule development in rice (Oryza sativa) by deep sequencing. Plant Cell Rep 36(11):1815-1827. https://doi.org/10.1007/s00299-017-2196-y

Wu F, Zhang D, Muvunyi BP, Yan Q, Zhang Y, Yan Z, Cao M, Wang Y, Zhang J (2018) Analysis of microRNA reveals cleistogamous and chasmogamous floret divergence in dimorphic plant. Sci Rep 8(1):6287. https://doi.org/10.1038/s41598-018-24477-x

Wuest SE, Vijverberg K, Schmidt A, Weiss M, Gheyselinck J, Lohr $\mathrm{M}$ et al (2010) Arabidopsis female gametophyte gene expression map reveals similarities between plant and animal gametes. Curr Biol 20:506-512. https://doi.org/10.1016/j.cub.2010.01.051 
Xie F, Jones DC, Wang Q, Sun R, Zhang B (2015) Small RNA sequencing identifies miRNA roles in ovule and fibre development. Plant Biotechnol J 13(3):355-369. https://doi.org/10.1111/pbi.12296

Yang WC, Ye D, Xu J, Sundaresan V (1999) The SPOROCYTELESS gene of Arabidopsis is required for initiation of sporogenesis and encodes a novel nuclear protein. Genes Dev 13(16):2108-17. https://doi.org/10.1101/gad.13.16.2108

Yang L, Wu Y, Wang W, Mao B, Zhao B, Wang J (2017) Genetic Subtraction profiling identifies candidate miRNAs involved in rice female gametophyte abortion. G3 Bethesda 7(7):2281-2293

Yao X, Chen J, Zhou J, Yu H, Ge C, Zhang M, Gao X, Dai X, Yang ZN, Zhao Y (2019) An essential role for miRNA167 in maternal control of embryonic and seed development. Plant Physiol 180(1):453-464. https://doi.org/10.1104/pp.19.00127

Yelina E, Smith LM, Jones AME, Patel K, Kelly KA, Baulcombe DC (2010) Putative Arabidopsis THO/TREX mRNA export complex is involved in transgene and endogenous siRNA biosynthesis. Proc Natl Acad Sci USA 107(31):13948-13953. https://doi.org/ 10.1073/pnas.0911341107

Yoshikawa M, Peragine A, Park MY, Poethig RS (2005) A pathway for the biogenesis of trans-acting siRNAs in Arabidopsis. Genes Dev 19(18):2164-75. https://doi.org/10.1101/gad.1352605

Yu B, Yang Z, Li J, Minakhina S, Yang M, Padgett RW, Steward R, Chen X (2005) Methylation as a crucial step in plant microRNA biogenesis. Science 307:932-935. https://doi.org/10.1126/scien ce. 1107130

Yu B, Bi L, Zhai J, Agarwal M, Li S, Wu Q, Ding SW, Meyers BC, Vaucheret H, Chen X (2010) siRNAs compete with miRNAs for methylation by HEN1 in Arabidopsis. Nucleic Acids Res 38(17):5844-5850. https://doi.org/10.1093/nar/gkq348
Zhai L, Sun W, Zhang K, Jia H, Liu L, Liu Z, Teng F, Zhang Z (2014) Identification and characterization of argonaute gene family and meiosis-enriched argonaute during sporogenesis in maize. J Integr Plant Biol 56(11):1042-1052. https://doi.org/10.1111/ jipb. 12205

Zhang F, Dong W, Huang L, Song A, Wang H, Fang W, Chen F, Teng N (2015) Ident. of MicroRNAs and their targets associated with Embryo abortion during Chrysanthemum cross breeding via high-throughput sequencing. PLoS One 10(4):e0124371. https:// doi.org/10.1371/journal.pone.0124371

Zhao T, Xu X, Wang M, Li C, Li C, Zhao R, Zhu S, He Q, Chen J (2019) Ident and profiling of upland cotton microRNAs at fiber initiation stage under exogenous IAA application. BMC Gen 20(1):421. https://doi.org/10.1186/s12864-019-5760-8

Zhao X, Bramsiepe J, Van Durme M, Komaki S et al (2017) Science 356(6336):eaaf6532. https://doi.org/10.1126/science.aaf6532

Zhong X, Du J, Hale CJ, Gallego-Bartolome J, Feng S, Vashisht AA, Chory J, Wohlschlegel JA, Patel DJ, Jacobsen SE (2014) Molecular mechanism of action of plant DRM de novo DNA methyltransferases. Cell 157(5):1050-60. https://doi.org/10.1016/j.cell. 2014.03.056

Publisher's Note Springer Nature remains neutral with regard to jurisdictional claims in published maps and institutional affiliations. 